\title{
3D structure of a Brucella melitensis porin: molecular modelling in lipid membranes
}

\author{
Lopes-Rodrigues M, Zanuy D, Aleman C, Michaux C, Perpète EA
}

C. Michaux and EA. Perpète contributed equally to this work.

\begin{abstract}
Brucella melitensis is a pathogenic bacterium responsible for brucellosis in mammals and humans. Its outer membrane proteins control the diffusion of solutes through the cell, and they consequently have a crucial role in the design of new diagnostics and vaccines. In this work, we have investigated the structure and dynamics of the Brucella melitensis porin Omp2a, combining a threading method and all-atom molecular dynamics simulations in lipid bilayers.

The model proposed for Omp2a shows structural characteristics similar to bacterial porins such as Phosphoporin and $\mathrm{OmpF}$, enhancing the relevance of the predicted structure. Moreover, molecular dynamics simulations demonstrate the stability with time of both the barrel and its inner channel placed in an environment mimicking the natural membrane. It is shown that the structure is well retained in the three systems while the POPE membrane tends to reduce the size of the inner pore. The gathered information on structure will help to understand the Omp2a functions and promote the development of new nanotechnologies and vaccine applications.
\end{abstract}

Keywords: porin, molecular dynamics, structure-function relationships, threading

\section{Introduction}


Brucellosis is the most common zoonotic infection provoked by the gram-negative bacteria Brucella family that can infect mammals, mainly ovine and caprine, as well as humans (Pappas, Papadimitriou, Akritidis, Christou, \& Tsianos, 2006). Six species have been identified amongst this genus: $B$. abortus from cattle, $B$. melitensis from sheep and goats, $B$. suis from pigs, B. ovis from sheep and B. neotamae from rats (De Figueiredo, Ficht, RiceFicht, Rossetti, \& Adams, 2015). Despite its fame, the mechanisms of this pathogenic bacteria family have still to be described. Therefore, the structure and function of the Brucella outer membrane proteins (OMP) are studied, paving the way to efficient diagnostic and vaccine applications. Amongst those OMP, the porin subfamily is responsible for the diffusion of hydrophilic molecules such as ions, amino acids, nutrients or drugs through the cell membrane. Hence, porins are involved in antibiotic resistance and for this reason, they are a key target in drug development (Galdiero et al., 2012; Pagès, James, \& Winterhalter, 2008).

Brucella melitensis has a high pathogenicity and this work focus on one of its major OMP: Omp2a, a 39 kDa nonspecific trimeric porin (DelVecchio et al., 2002) that was recently shown to be a potential antigen candidate for serodiagnosis of human brucellosis (Pathak, 2017). Outer membrane (OM) permeability assays indicated that Omp2a increases the hydrophilic permeability of E. coli, consistent with pore-forming activity (Marquis \& Ficht, 1993). An E. coli transformant producing Omp2a has an increased hydrophilic permeability to maltose, and that is able to grow on maltotetraose.

As a membrane protein, Omp2a represents a challenge to produce, refold and crystallize. Indeed, this type of protein requires an adapted environment to retain its functional and native state. Extracted from the amphiphilic lipid bilayer, membrane proteins become unstable; they unfold and tend to aggregate. To circumvent the absence of the cell membrane, detergents are used as amphiphiles (Moraes, Evans, Sanchez-weatherby, Newstead, \& Shaw, 2014). Omp2a has been produced in inclusion bodies and successfully refolded. Indeed, our group successfully demonstrated the formation of Omp2a trimers, similarly to other general porins of other species (G. Roussel, Matagne, De Bolle, Perpète, \& Michaux, 2012a; Guillaume Roussel, Perpète, Matagne, Tinti, \& Michaux, 2013). Using a comparable production method, nanoscale polymers including the functional Omp2a were prepared. Those innovative materials have shown increased and preferential diffusion of ions after the inclusion of the proteins (Pérez-Madrigal et al., 2015; Puiggalí-jou et al., 2016). 
Whilst an efficient production protocol has been described increasing the interest engendered by Omp2a, still no experimental 3D structure has been determined to the best of our knowledge. When crystallographic data are not available, computational topology prediction methods are an alternative of choice to access the structural and functional properties of the proteins. Homology modelling is the most reliable method but it requires experimental structural data of homologous proteins, which cannot be found in the case of Omp2a. Indeed, $\beta$-barrel porins are known to have highly conserved structures, but sharing very low sequence identity (Feher et al., 2013). Nevertheless, these proteins conserve features that help for the recognition of a $\beta$-barrel, such as (i) an even number of antiparallel trans-membrane strands, (ii) a high content of hydrophobic residues facing the aliphatic chains of the membrane lipids, (iii) a constriction $\alpha$-helix loop -called L3- at the middle of the pore, and also (iv) girdles of aromatic residues at the extremities of the barrel (Jackups \& Liang, 2005). Previous topology studies, based on..., predicted that Omp2a was a 16 -stranded $\beta$-barrel with long loops on the external side of the barrel and short turns on the internal side (Mobasheri, Ficht, Marquis, Lea, \& Lakey, 1997; Paquet, Vinals, Wouters, Letesson, \& Depiereux, 2000).

In this work, the first 3D-model of the trimeric Brucella melitensis Omp2a is proposed. This structure is subsequently embedded in phospholipid bilayers in order to study its stability in an environment of technological interest. A better understanding of the Omp2a structure and function would lead to improved new bio-composite polymers and would help designing new brucellosis vaccines.

\section{Methods}

\subsection{D-model prediction by threading. The RaptorX webserver} (http://raptorx.uchicago.edu) is used to predict both the secondary and tertiary structure by the threading method (Källberg et al., 2012). It is a template-based modelling (TBM) method using statistical knowledge of the relationship between the structures deposited in the Protein Data Bank (PDB) and the sequence of the interest protein (Ma, Wang, Zhao, \& $\mathrm{Xu}, 2013$ ). The prediction is made by "threading" (i.e. placing, aligning) each amino acid in the target sequence to a position in the template structure, and evaluating how well the target fits the template. The quality of the predicted model depends on the alignment of the 
sequences and the templates (domains or whole protein) selection. The reliability of the model is then checked by Ramachandran analysis using Rampage (ref: Lovell), while the secondary structure content is evaluated by the DSSP algorithm (REF).

The GalaxyGemini webserver (http://galaxy.seoklab.org) has subsequently been used to predict the oligomeric state of the model (Lee, Park, Ko, \& Seok, 2013). It compares the sequence (à quoi?) of the input and superimposes the structure with known templates. The predicted oligomeric state has then the same state than the best selected template and the quaternary structure is then optimized by energy minimization. The radius of the channel has been measured by the HOLE software (Smart, Neduvelil, Wang, Wallace, \& Sansom, 1996).

2.2 Docking studies. Docking of potential Omp2a substrates (maltose and maltotetraose) was performed into an Omp2a monomer channel using the GOLD program (Jones, 1997). GOLD is based on a genetic algorithm (GA) that performs the docking of flexible ligands into proteins, including partial flexibility in the neighbourhood of the active site. The binding region was defined as a $20 \AA$ radius sphere centred on Tyr133, facing the centre of the channel. For each of the $20 \mathrm{GA}$ runs, a total of 100000 genetic operations were carried out on 5 islands, each containing 100 individuals. The niche size was set to 2 , and the value for the selection pressure was set to 1.1. Genetic operator weights for crossover, mutation and migration were set to 95,95 and 10, respectively. The solutions were then ranked by GOLD score.

2.3 Molecular Dynamics. Molecular Dynamics all-atom simulations were performed by using the GROMACS 5.0.2 software (Abraham et al., 2015; Berendsen, van der Spoel, \& van Drunen, 1995). Both the insertion of the protein by replacement method and the construction of the lipid bilayer were achieved by CHARMM-GUI webserver (Jo, Kim, \& Im, 2007). Simulations systems consist of cubic boxes of $12 \times 12 \times 10 \mathrm{~nm}$. Water thickness was set to $2.0 \mathrm{~nm}$ on both side, corresponding to approximatively 25000 water molecules in total. Bilayers consist of 284 1-palmitoyl-2-oleoyl-sn-glycero-3-phosphocholine (POPC), 331 1-palmitoyl-2-oleoyl-sn-glycero-3-phosphoethanolamine (POPE) and 154 POPC+154 POPE for system A, B and C, respectively. Arginine and lysine residues are protonated while aspartate and glutamate are negatively charged. This protonation is associated to a $\mathrm{pH}$ value 
of 7.4. The monomeric protein overall net charge is therefore -18.54 potassium cations were therefore placed by Monte-Carlo method to neutralize the trimeric protein.

The selected force-field is Charmm36 and additional parameters for lipids were taken from CHARMM-GUI (Huang \& Mackerell Jr, 2013). The three-site water model TIP3P was used to describe the solvent, whereas periodic boundary conditions were applied in all directions. $\mathrm{H}$ bonds were constrained with the linear constraint solver (LINCS) algorithm (Hess, Bekker, Berendsen, \& Fraaije, 1997). The Verlet cut-off scheme of $1.2 \mathrm{~nm}$ was used for pair interactions, while the cut-off distance for Van der Waals and electrostatic interactions was set to $1.2 \mathrm{~nm}$. The electrostatic interactions were described via the particle-mesh Ewald (PME) method (Essmann et al., 1995), and the steepest descent method was chosen for the energy minimisation.

Production simulations ran in the NPT ensemble with a time step of $2 \mathrm{fs}$, with protein, lipids, ions and water independently coupled with a Nose-Hoover thermostat at $298 \mathrm{~K}$ to keep a temperature above the phase transition temperature ( $270 \mathrm{~K}$ for POPC and $290 \mathrm{~K}$ for POPE) (Leekumjorn \& Sum, 2007). Pressure was kept constant to 1 bar by the semi-isotropic Parrinello-Rahman pressure coupling algorithm.

Analyses were performed by integrated GROMACS programs and by Visual Molecular Dynamics (VMD) (Humphrey, Dalke, \& Schulten, 1996). Membranes thickness and area per lipids were calculated by the GridMat-MD software (Allen, Lemkul, \& Bevan, 2009).

\section{Results and discussion}

\subsection{D model of Omp2a: structural analysis.}

The Omp2a sequence (reference number: Q7CNU3) from Brucella melitensis, excluding the $\mathrm{N}$-terminal sequence of the signal peptide (51 residues), was submitted to the RaptorX webserver (Källberg et al., 2012) to obtain a structural starting point, while the Phosphoporin (PhoE) (pdb: 1pho with $3.00 \AA$ A resolution, from E. coli) was selected as the best template (Cowan et al., 1992). The second and third best templates are two OmpF structures (pdb: 3hw9 and 3nsg, with $2.61 \AA$ and $2.79 \AA$ resolution, respectively), both gramnegative bacteria from E. coli and S. typhimurium (Balasubramaniam, Arockiasamy, Kumar, Sharma, \& Krishnaswamy, 2012; Dhakshnamoorthy, Raychaudhury, Blachowicz, \& Roux, 2010). Both PhoE and OmpF are 16-stranded $\beta$-barrels general porins. In order to evaluate 
the quality of the Omp2a model, the alignment score and the P-values are taken into account. The alignment score goes from 0 to 100 with 100 representing a perfect model. A score higher than 50 is likely to provide a correct structure (Källberg et al., 2012). The score for Omp2a model aligned with the templates 1 pho, 3hw9 and 3nsg are respectively 81, 79 and 66, which suggests our model is well relevant. The P-value expresses the probability of the predicted model to be less realistic than a set of randomly-generated models of the same protein. For $\beta$-proteins, a P-value less than $10^{-4}$ is a good indicator (Källberg et al., 2012). The Omp2a PhoE-based model has a P-value of $3.2610^{-6}$ suggesting a good starting point to allow going further in the analyses and assessing the quality of the model by comparison with other known porins.

Following the Ramachandran analysis, $90 \%$ of the residues are in the most-favorable region, $8 \%$ in the allowed region and $2 \%$ are outliers. All the outliers are found on the extracellular loops and except GLY168, which is on the L3 loop inside the pore. Interestingly, a similar analysis of the PhoE crystal structure also shows nine outliers mostly located on the loops (Cowan et al., 1992). The outliers of Omp2a may therefore be inherent to the template used to build the model. On the other hand, the large extracellular loops are known to be versatile, with a high content of disordered structure. These conformational errors can therefore be neglected for the following analyses. For the GLY168, it is difficult to distinguish any inaccuracy related to a genuine structural feature, as glycine residues may adopt several conformations (Lovell et al., 2003).

Omp2a is a well-defined 16-stranded $\beta$-barrel with both $\mathrm{N}$ - and C-terminus located on the periplasmic side (Figure 1). $\beta$-strands are separated by 8 long loops (L) on the extracellular side, and by 7 short turns $(T$ ) on the periplasmic side (Figure 2). The third long loop (L3) folds inside the barrel and forms a bottleneck called the constriction zone. This corroborates the previously predicted topology, as well as the general structure of known bacterial porins (Mobasheri et al., 1997; Paquet, Vinals, Wouters, Letesson, \& Depiereux, 2000b; Schulz, 2000; Zeth \& Thein, 2010).

One notable feature of such $\beta$-barrel construction is the presence of two girdles of aromatic residues located at the extremities of the barrel and facing towards the membrane-solvent interface (Schulz, 2000), while the side chains of these aromatic residues face towards the membrane-water interface. Our model respects this rule with 22 aromatic residues, as 10 PHE and 3 TYR are located on the lower girdle, whereas 2 PHE, 4 TYR and 3 
TRP can be found on the upper girdle (Figure 3). This feature typical of porins stabilizes the protein when it is embedded in the natural membrane, as a result of the formation at the lipid-water interface of $\mathrm{H}$-bonds between the side chains of TYR and TRP with the lipids' head groups. Note that accordingly to the literature (Im \& Roux, 2002b; Korkmaz, Köster, Yildiz, \& Mäntele, 2008), The PHE side chains point towards the lipid core.

In a second step, we calculated the secondary structure content of our model as well as phosphoporin and OmpF crystal structures, and we then compared to the Omp2a experimental circular dichroism (CD) data (Table 1) (G. Roussel, Matagne, De Bolle, Perpète, \& Michaux, 2012b; Touw et al., 2015). The percentage of each secondary structure in the model is in the same range as in the $C D$, taking into account that the $C D$ values are extracted from a structure in solution. In addition, the results are in good agreement with literature, which reports a majority $\%$ of $\beta$-strands followed by a high $\%$ of coil in the extracellular loops for several bacterial porins (Vollan, Tannæs, Vriend, \& Bukholm, 2016). In our model, the $\beta$ strands \% are slightly smaller than in the other porins but the dimensions of the barrel are well retained: $3.5 \mathrm{~nm}$ in width for $4.5 \mathrm{~nm}$ in height (Zeth \& Thein, 2010).

Table 1: Secondary structure content (\%) calculated by DSSP for the Omp2a model and the crystal structures of Phosphoporin and OmpF. In brackets are the deconvoluted values from experimental data by Circular Dichroism.

\begin{tabular}{l|llll}
\multicolumn{2}{c}{$\boldsymbol{\beta}$-strands (\%) } & $\boldsymbol{\alpha}$-helices (\%) & Turns (\%) & Coil (\%) \\
\hline Omp2a & $51(40)$ & $3(8)$ & $10(24)$ & $33(27)$ \\
Phosphoporin & 56 & 2 & 11 & 31 \\
OmpF & 55 & 3 & 12 & 30
\end{tabular}

For OmpF and PhoE, the average residue number in $\beta$-strands is 10 and 11 , while it is 13 and 14, respectively, for extracellular flexible loops. In Omp2a, this number is 10 and 15 for $\beta$-strands and loops, respectively, in full agreement with other described $\beta$-barrel structures (Tamm, Hong, \& Liang, 2004). The largest discrepancies between the structures relate to the loops that exhibit high sequence variability and may contain genuine features for their specific function (Koebnik, Locher, \& Van Gelder, 2000).

\subsection{D model of Omp2a: function analysis.}

The porin channels show preferences for charge and size of the solute. Omp2a channels present 41 anions (ASP and GLU) and 23 cations (ARG and LYS). More than half 
(22) of the negative but only 6 positive charges are detected on the extracellular loops facing the external environment (Figure 4). The loops clearly shield the inner channel with a strong negative field. This particular distribution could explain the preferential diffusion of cations experimentally demonstrated for Omp2a embedded in nanomembranes (PérezMadrigal et al., 2015; Puiggalí-jou et al., 2016). The excess of negative charges at the top of the channel can attract free cations (e.g. $\mathrm{K}^{+}$or $\mathrm{Na}^{+}$) and repulse anions, leading to a local accumulation of cations and their further diffusion (Tien \& Ottova-Leitmannova, 2003). Omp2a has the same preference than OmpF, unlike PhoE preferring anions over cations (Microbiol Mol Biol Rev. 2003 Dec; 67(4): 593-656).

A close look to $\mathrm{L} 3$ entering the $\beta$-barrel can also provide insights about the function of the protein. In porins, this loop folds into a short $\alpha$-helix that restricts the size of the inner channel in a so-called "constriction zone" or "eyelet". The latter is constituted of two sides; the first one is the above mentioned L3 loop, while the second is the inner part of the $\beta$ barrel wall facing the loop. The Omp2a $\alpha$-helix located on the L3 loop is 10 residues long, while OmpF and PhoE helices are 8 and 7 residues long, respectively (Zeth \& Thein, 2010). All these L3 loop sequences have a poor identity percentage except for OmpF and PhoE that share the highly conserved motif PEFGG found in enterobacteria (Jeanteur, Lakey, \& Pattus, 1991; Koebnik et al., 2000). The chemical properties of the restricting loop are compared in Table 2. In all proteins, L3 presents a high content of apolar residues combined to an excess of negatively charged residues (Bigelow, Petrey, Liu, Przybylski, \& Rost, 2004). As observed in classical porins, the majority of polar and charged residues of the Omp2a L3 loop face towards the inner side of the channel in order to create a hydrophilic cavity (Figure 5).

Table 2: Number and type of residues constituting the L3 loops of the Omp2a model, PhoE, and two OmpF. Number in parenthesis is the length (in residues) of the L3 loop.

\begin{tabular}{l|llll} 
& Polar & Apolar & Positive & Negative \\
\hline Omp2a (23) & 6 & 13 & 0 & 4 \\
PhoE (30) & 7 & 16 & 1 & 6 \\
OmpF (E. coli)(29) & 3 & 20 & 0 & 6 \\
OmpF (S. typh.)(30) & 8 & 16 & 1 & 5
\end{tabular}

The L3 loop residues facing the cavity amount to 1 positively charged, 4 negatively charged, 3 polar and 7 apolar residues, while the other side of the cavity is composed of 6 positively 
charged (all arginines), 10 polar and 5 apolar residues. The channel is therefore clearly separated in two charged subsets: the negative L3 loop and the positive barrel wall (Figure 5). This particular distribution was previously reported for other porins and is supposed to generate the electrostatic field controlling the diffusion of the hydrophilic solutes, such as sugars or ions (Phale et al., 2001). In addition, this can also explain the two separated pathways for the diffusion of cations and anions (Im \& Roux, 2002a, 2002b; Niramitranon, Sansom, \& Pongprayoon, 2016).

The minimum pore radius of the inner channel $\left(R_{\min }\right)$, corresponding to the constriction zone at middle height of the barrel (Figure 6-7), was found to be $0.372 \mathrm{~nm}$, slightly larger than the ones of PhoE $(0.311 \mathrm{~nm})$ and $\mathrm{OmpF}(0.337 \mathrm{~nm}$ and $0.356 \mathrm{~nm}$ for $E$. coli and S. typhimurium, respectively). To support the experimental permeability assays (Marquis \& Ficht, 1993), docking studies were performed to show the availability of the Omp2a pore for both maltose and maltotetraose sugars. Several binding modes may be retained due to the flexibility of the sugar chain but most of them confirm that maltotetraose is able to travel through the Omp2a pore. As an illustration, Figure $8 \mathrm{a}$ and $8 \mathrm{~b}$ show two energetically favourable positions of the maltotetraose in the channel. The first (Figure 8c) is near the L3 loop while the other one (Figure 8d) lies along the barrel wall. In the first binding mode, the biomolecule interacts with Glu109, Tyr133, Asp126, Val127, while in the second one, it is in contact with Arg59, lle123, Arg13, Arg36. Moreover, the sugar is involved in several $\mathrm{H}$-bonds with the channel inner atoms, either with negative or positive residues (Figure $8 c-d$ ). These preliminary docking results support our Omp2a model displaying a pore able to host maltotetraose.

As experimentally demonstrated by our group, Omp2a is produced in native monomers that associate to form homotrimers (G. Roussel et al., 2012b; Guillaume Roussel et al., 2013), similarly to other classical porins (Galdiero et al., 2012). In agreement with these experimental data, GalaxyGemini indeed predicts a trimeric state for our model (Shin, Lee, Heo, Lee, \& Seok, 2014). The L2 loop is known to contribute to the stability of the trimeric form, affecting both its structure and its thermal denaturation (Phale et al., 1998). It is indeed observed reaching over to neighbouring subunits, and forming polar and ionic intersubunit interactions. Moreover, our modelling indicates that the trimeric state is stabilized by 101 hydrogen bonds, with half of them involved in interactions with L2 loops. In addition, residues Arg119 and Asp129 on Loop2 form salt bridges with Asp143 and Arg87 
in the adjacent subunit, respectively (Figure 9). Note that in addition to $L 2$, the strands 1-5 and 16 are also involved in the interface interactions.

\subsection{Molecular dynamics}

In order to assess the Omp2a trimeric model conformational stability in several lipid bilayer membranes mimicking its natural environment, molecular dynamics simulations were performed. The Brucella outer membrane phospholipid composition is roughly constituted of 50\% 1-palmitoyl-2-oleoyl-sn-glycero-3-phosphocholine (POPC) and 50\% 1palmitoyl-2-oleoyl-sn-glycero-3-phosphoethanolamine (POPE) (Moriyón \& López-Goñi, 1998). POPE is also present as the main lipid in the E. coli membrane, while POPC is not found in this specie. The Omp2a trimer was therefore embedded in three model lipid bilayers: POPC, POPE, and a 50/50 mixture of randomly placed POPC/POPE, optimally representing the Brucella outer membrane. As our model is based on E. coli protein templates and shares many features with $\mathrm{OmpF}$ and $\mathrm{PhoE}$, it is interesting to study the effect of the membrane nature on the protein stability.

To evaluate the relevance of our model bilayer, the area per lipid (APL), as well as the membrane thickness were compared to experimental data (Leekumjorn \& Sum, 2007). The average APL during the simulation is $0.62 \AA^{2}, 0.54 \AA^{2}$ and $0.59 \AA^{2}$ for the POPC, POPE and POPC/E bilayers, respectively. This is in perfect agreement with the corresponding experimental values of $0.62 \AA^{2}, 0.53 \AA^{2}$ and $0.58 \AA^{2}$, respectively. On the other hand, the average thickness is only slightly overestimated, with $3.98 \mathrm{~nm}$ (POPC), $4.45 \mathrm{~nm}$ (POPE) and $4.32 \mathrm{~nm}$ (POPC/POPE), which compare to experimental values of $3.88 \mathrm{~nm}$ (POPC), $4.31 \mathrm{~nm}$ (POPE) and $4.10 \mathrm{~nm}$ (POPC/E). This is explained by the lipids that directly surround the protein whose height is higher than the membrane. They arrange themselves to fit the protein and tend to slightly extend the thickness of the membrane. Especially the POPC/E bilayer seems to require more time to equilibrate. At the end of the simulation, 92 POPC, 101 POPE and 49 POPC+49 POPE for the blend are in contact with the protein, reflecting the APL values and suggesting that POPC occupies more space than POPE due to its more bulky polar head. Furthermore, the interactions between the trimer and the lipids cause local membrane thinning around the protein, especially in the mixed membrane (Figure 10), meaning that the protein induces more perturbation on its lipidic direct environment. Additionally, it is also noteworthy that the POPC/E membrane adapts to the trimeric 
protein, which shows limited shape changes during the simulation. By contrast, the protein in the POPC and POPE membranes significantly extends its volume.

In all three systems, the $\beta$-sheet content is decreasing by a very few amounts to the benefit of unstructured loops. The $\beta$-barrel pores are nevertheless stable but tend to quit their original cylinder shape to adopt an elliptical cylinder structure. The $\alpha$-helix L3 is always preserved, though its length and orientation are changed. This is notable in the POPE membrane, in which L3 undergoes a longer length than in the other membranes. In addition, the average number of hydrogen bonds at the interface of the monomers increases during the simulation by $10 \%(36 \%), 20 \%(39 \%)$ and $25 \%(41 \%)$ for the POPC, POPE and $P O P C / E$, respectively, stabilizing the quaternary structure due to the effect of the surrounding lipids.

The RMSF (root mean square fluctuation) shows that the extracellular loops $L 1,3,4$, 6 and 8 are the most versatile part of the protein in all three membranes (Figure). Such variations in the loops can generally be related with their respective length. Indeed, L5 and L7 are the shortest with 9 and 4 residues, respectively and have less movement among time than the others. Whilst $L 2$ is the longest loop responsible of the protein-protein interactions in the quaternary structure, it is subjected to the smallest fluctuation. The $\alpha$-helix L3 appears to be less stable in the POPE membrane, and this corroborates the observation of an increase in $\alpha$-helix content in such environment.

The analysis of the $R_{\min }$ variation calculated along the channel vector during the simulations shows that the channel is not static and undergoes breathing-like motions from the initial configuration $\left(R_{\min }: 0.372 n m\right)$. Indeed, the constriction zone fluctuates by subsequently growing and shrinking, around a mean radius value of $2.42 \AA, 2.12 \AA$ and 2.94 $\AA$ for the POPC, POPE and POPC/E membranes, respectively.

It is important to note that the MD simulations tend to underestimate the size of the cavity (Varma, Chiu, \& Jakobsson, 2006). The average time for the opening-closing movement is about 40 ns with an amplitude of $1 \AA$ in general (up to $2 \AA$ in some extreme cases). Meanwhile, the constriction zones show steady states for periods as long as $70 \mathrm{~ns}$. Considering that a $R_{\min }$ of $1.15 \AA$ is required for the diffusion of one water molecule and consequently that below this value, the channel is considered as totally close, we can assume the omp2a channel is always in an open state. 
The $\beta$-strands 2 and 3 carrying the inner pore residues, undergo important displacements in the POPC and POPE membranes (Figure 11). This behaviour is observed to a lower extent in the blend membrane, explaining a higher average $R_{\min }$ of the POPC/E system. In addition, the L3 loop which is responsible of the pore constriction (LopesRodrigues et al., 2018), is very flexible and tends to move towards the centre of the cavity while maintaining its polar residues always facing the channel side. Specifically in that loop, the side-chain of TYR118 undergoes strong rotations, from facing the edge of the barrel wall to the centre of the channel. The $\beta$-strands 2,3 , as well as loop 3 are therefore key elements regulating the size of the channel. Each monomer composing the Omp2a system seems to act independently of the others regarding the size of the channel. From a larger point of view, this can be explained by significant barrel walls stability.

\section{Conclusion}

In this work, we presented the first 3D structure of the Brucella melitensis porin Omp2a. It has been designed by following a threading procedure, and it shows the typical features found for resolved crystallographic structures of other known porins (i.e. OmpF and Phosphoporin). We present a 16-stranded $\beta$-barrel model with a well-defined $\alpha$-helix on the L3 loop folding inside the barrel and forming the constriction zone. In addition, two girdles of aromatic residues are located at the extremities of the barrel and face towards the membrane-solvent interface. They are hypothesized to have a role of stabilization when the protein is embedded in the natural membrane.

The extracellular loops facing the external environment clearly shield the inner channel with a strong negative field, explaining the preferential cations diffusion that has been experimentally demonstrated for Omp2a. The channel was observed to be separated into two charged clusters: the negative L3 loop on the one hand, and the positive barrel wall on the other hand. This peculiar distribution, previously reported for other porins, is supposed to generate an electrostatic field controlling the diffusion of the hydrophilic solutes, such as ions or sugars. A $R_{\min }$ of $0.372 \mathrm{~nm}$, as well as docking results support this Omp2a model displaying a pore able to host maltotetraose, able to cross the channel.

The monomer model has been assembled into a realistic trimer, which is stabilized due to the L2 loop forming polar and ionic intersubunit interactions. The stability of the trimer, embedded in three lipid bilayers (pure POPC, pure POPE and 1:1 POPC/POPE), was 
assessed by molecular dynamics studies. The three membranes all demonstrated their ability to maintain open the Omp2a channels open. As observed by the $R_{\min }$ variation, the channel undergoes breathing-like motions with the $\beta$-strands 2,3 and L3 respective morphology being the key elements regulating the size of the channel.

Furthermore, the POPC/E bilayer mimics the best the natural membrane, and it has shown a different behaviour compared to the others. Indeed, i) a local membrane thinning is observed around the protein; ii) the membrane adapts to the trimeric protein which shows few shape changes all along the MD simulation; iii) the narrowing of the pore is less pronounced during the simulation; iv) the trimer is also more stabilized by an increasing number of hydrogen bonds.

All these differences suggest that the lipid blend is more suited to preserve the integrity of the protein, and therefore its function. It would therefore be considered as a basis for future experimental reconstitution in liposomes, allowing to propose new proteinbased biomaterials and, in a therapeutic point of view, to design new vaccines targeting the protein. 


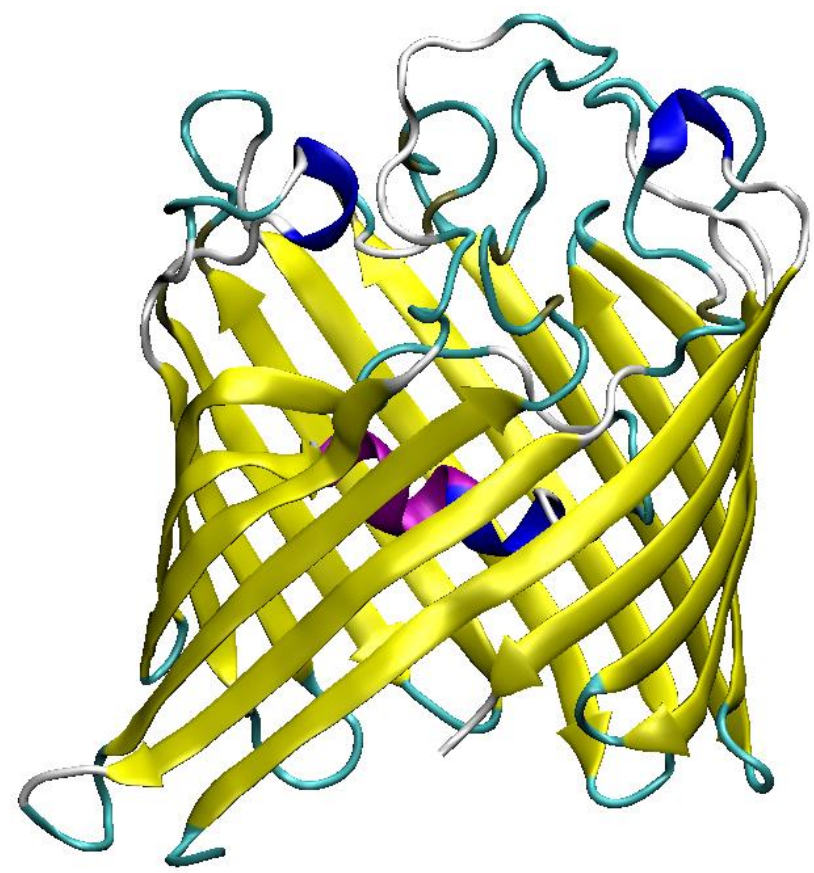

Figure 1: Omp2a predicted model by RaptorX. The model is a well defined $\beta$-barrel constituted of 16 antiparallel strands. Color legend: Yellow: $\beta$-sheet; cyan: turn; blue and mauve: $\alpha$-helix; white: coil. 


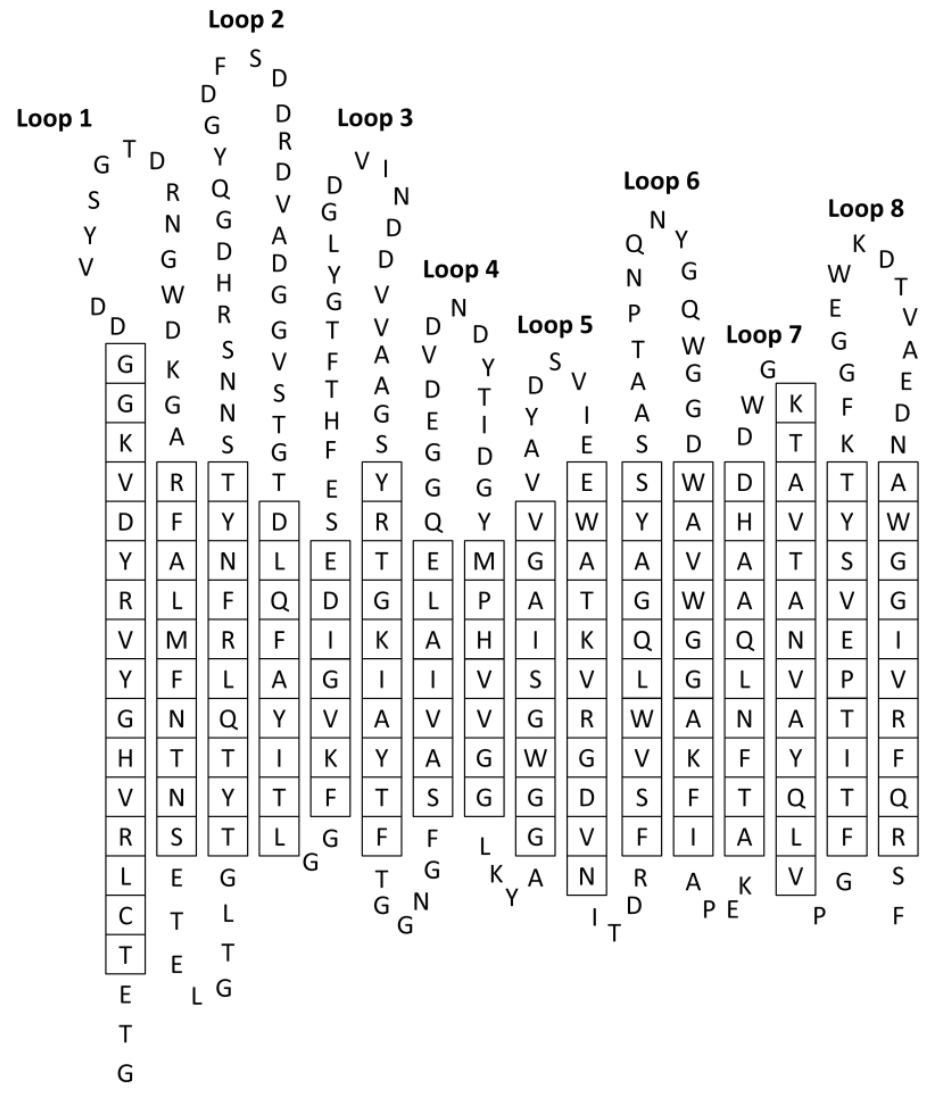

Figure 2: Omp2a topology prediction 


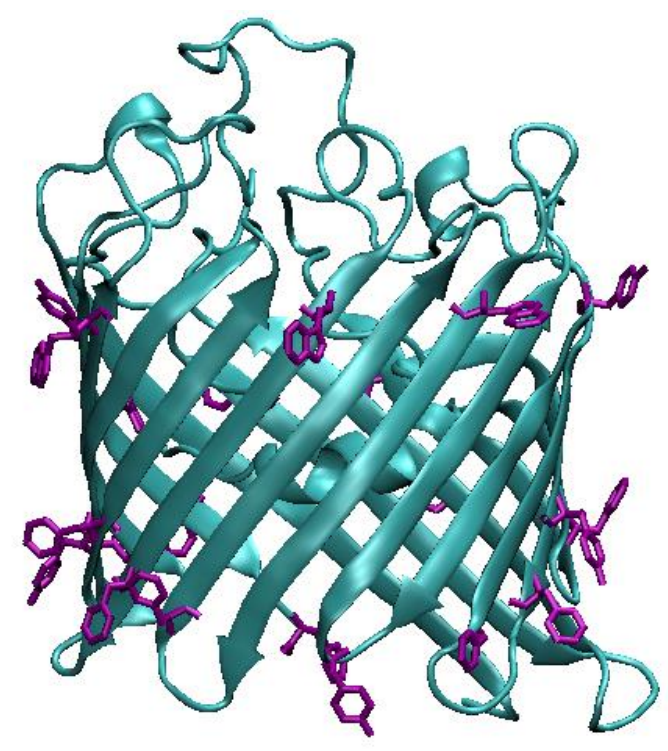

Figure 3: Aromatic girdles (in magenta) of the Omp2a model 


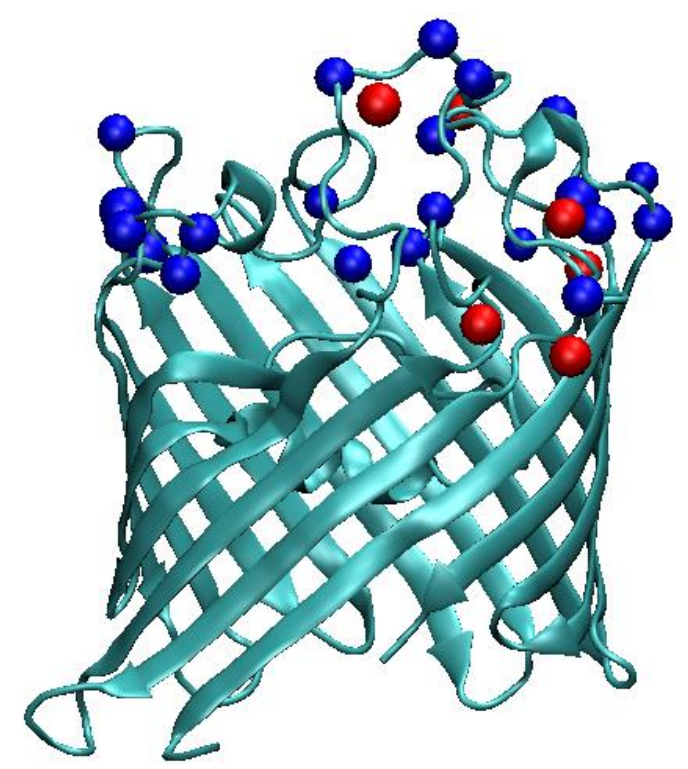

Figure 4: Charged residues located on the external loops of the Omp2a model. Blue balls and red balls represent ASP and GLU residues (negative) and ARG and LYS (positive), respectively.

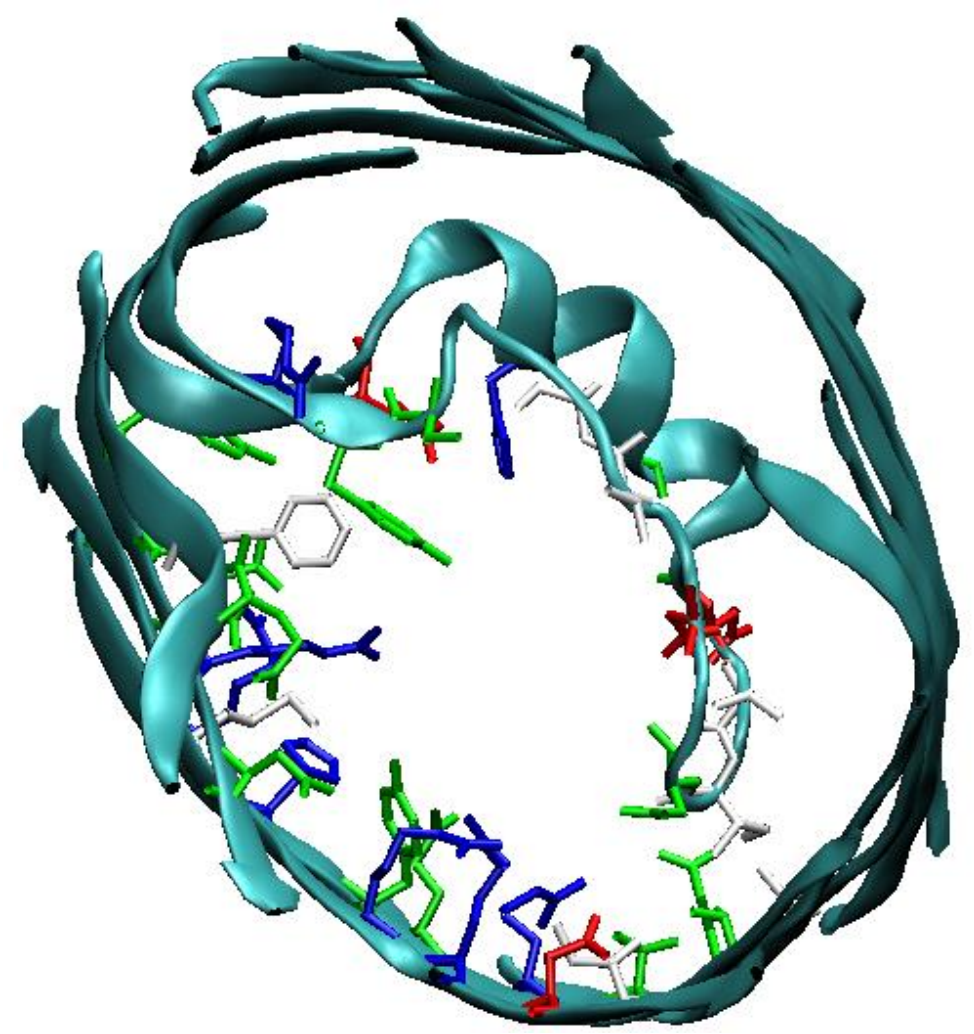

Figure 5: Inner channel residues of Omp2a. White are apolar, green are polar, red are positively charged and blue are negatively charged residues 


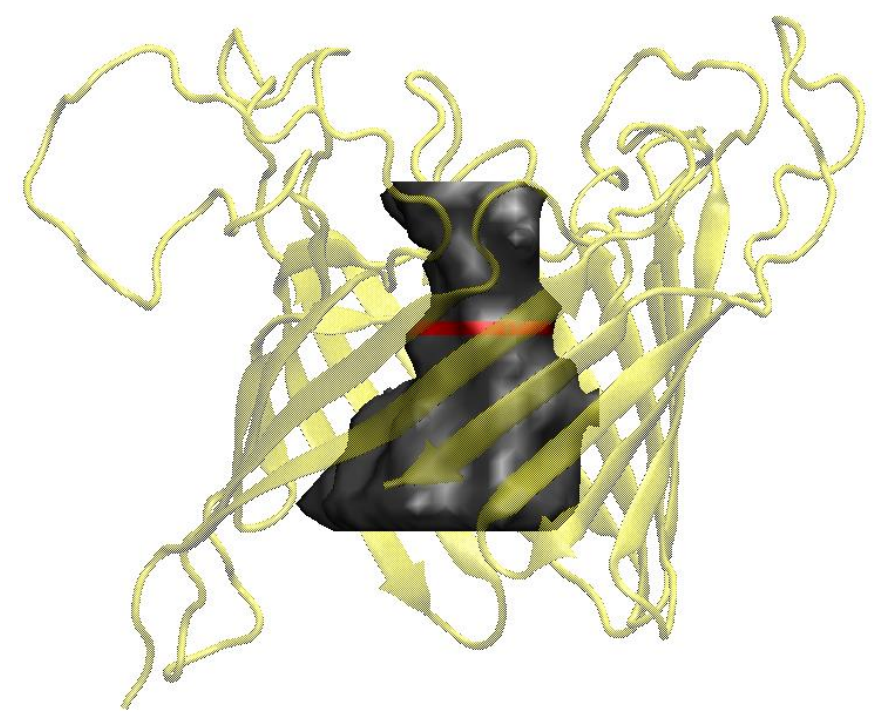

Figure 6: Inner cavity of the Omp2a model. The red line represents the constriction zone

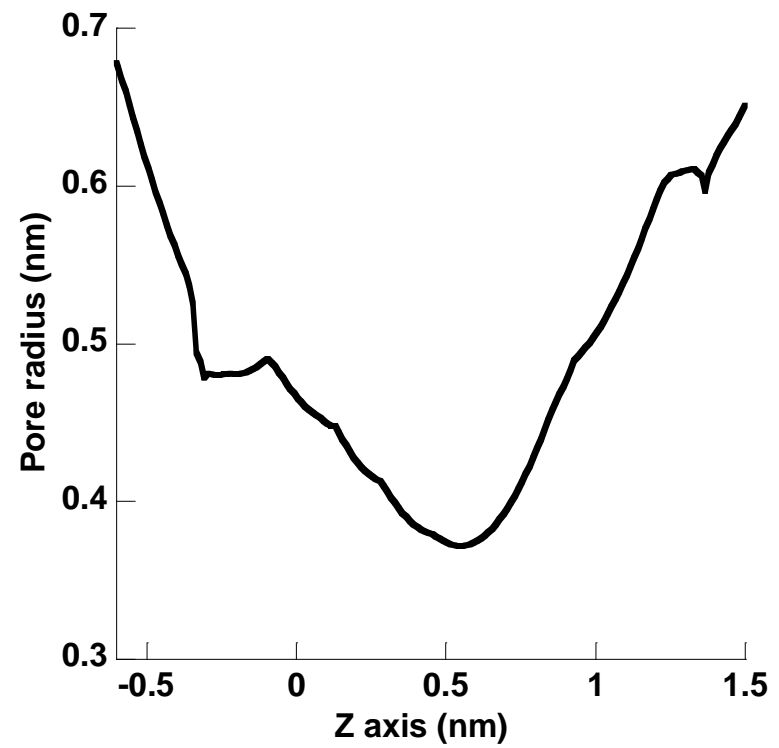

Figure 7: Omp2a pore radius along the $Z$ axis calculated by the HOLE programme 
a)

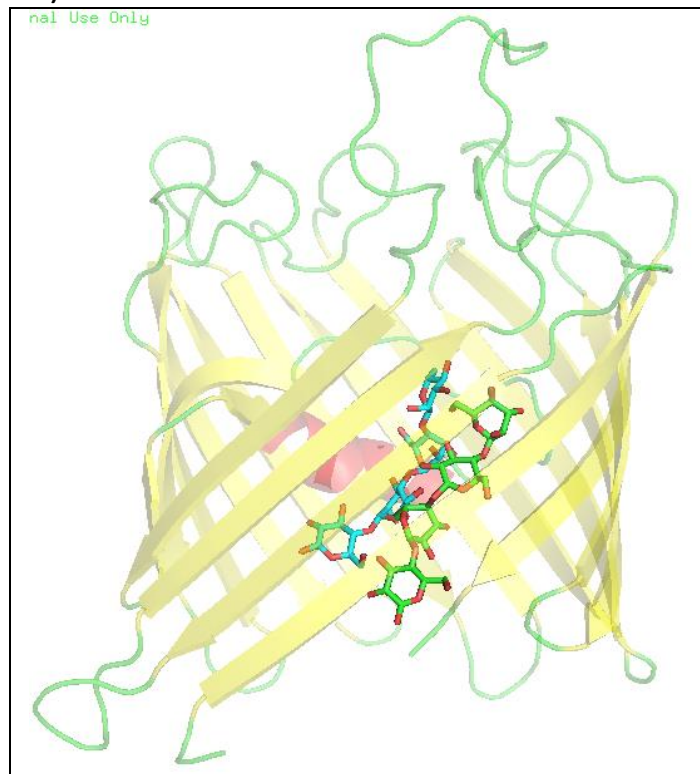

c)

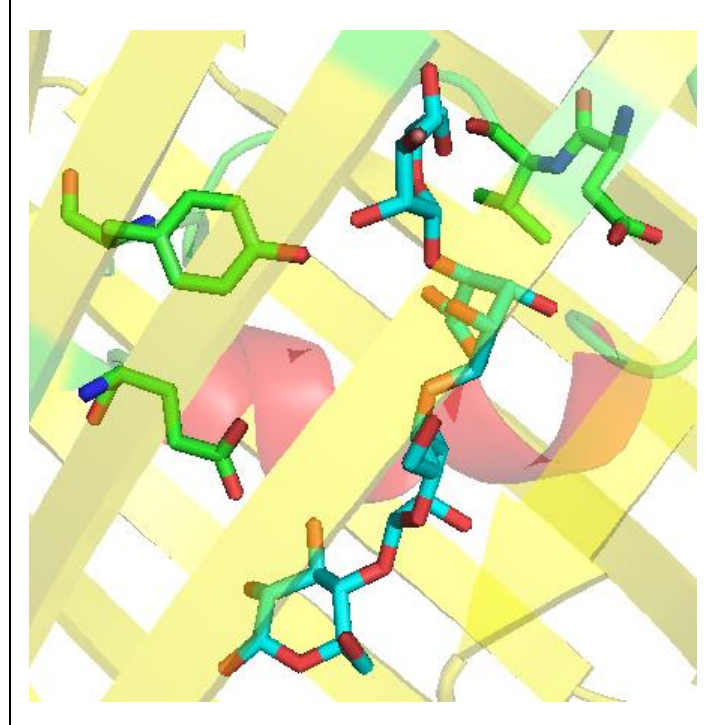

b)

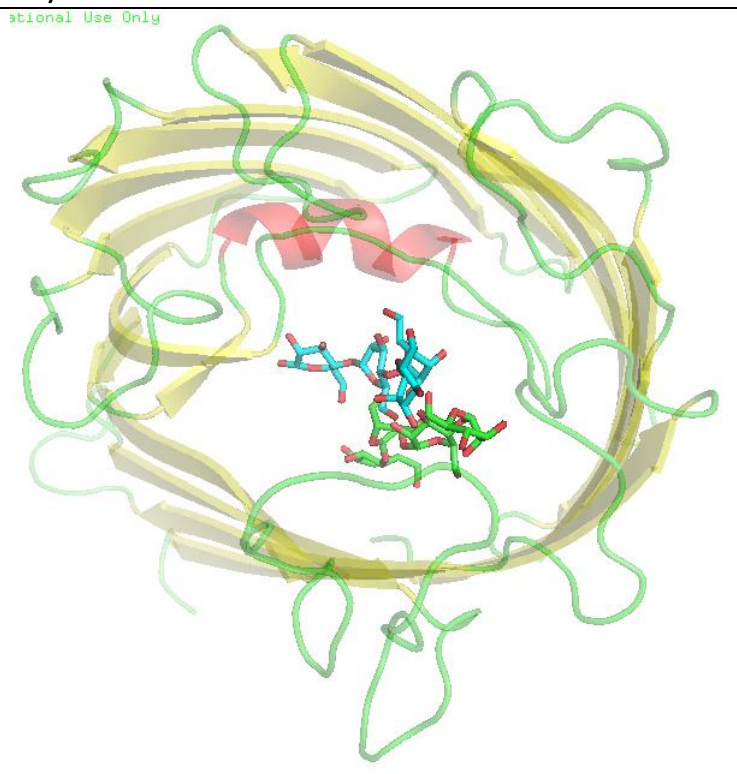

d)

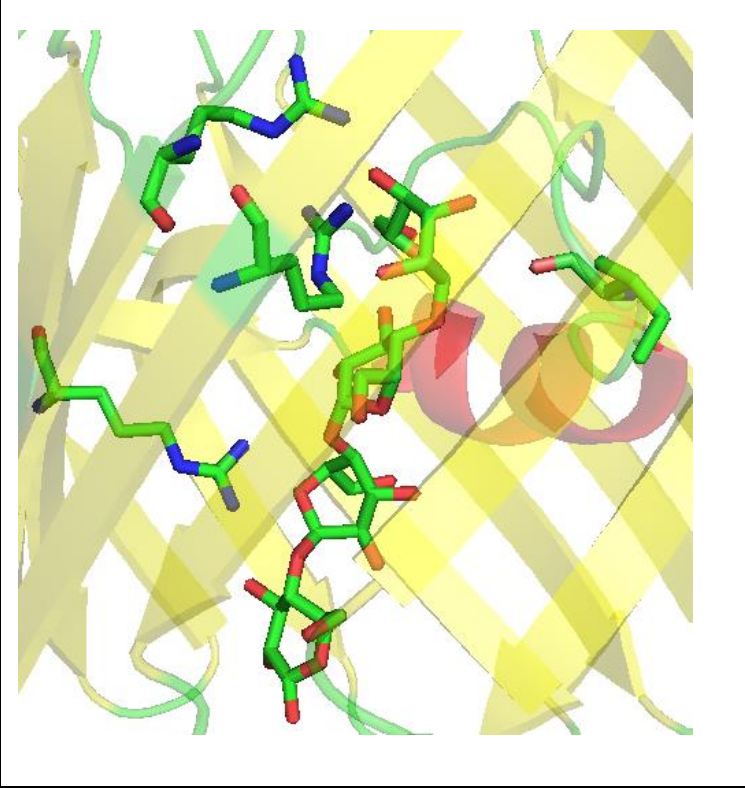

Figure 8: 


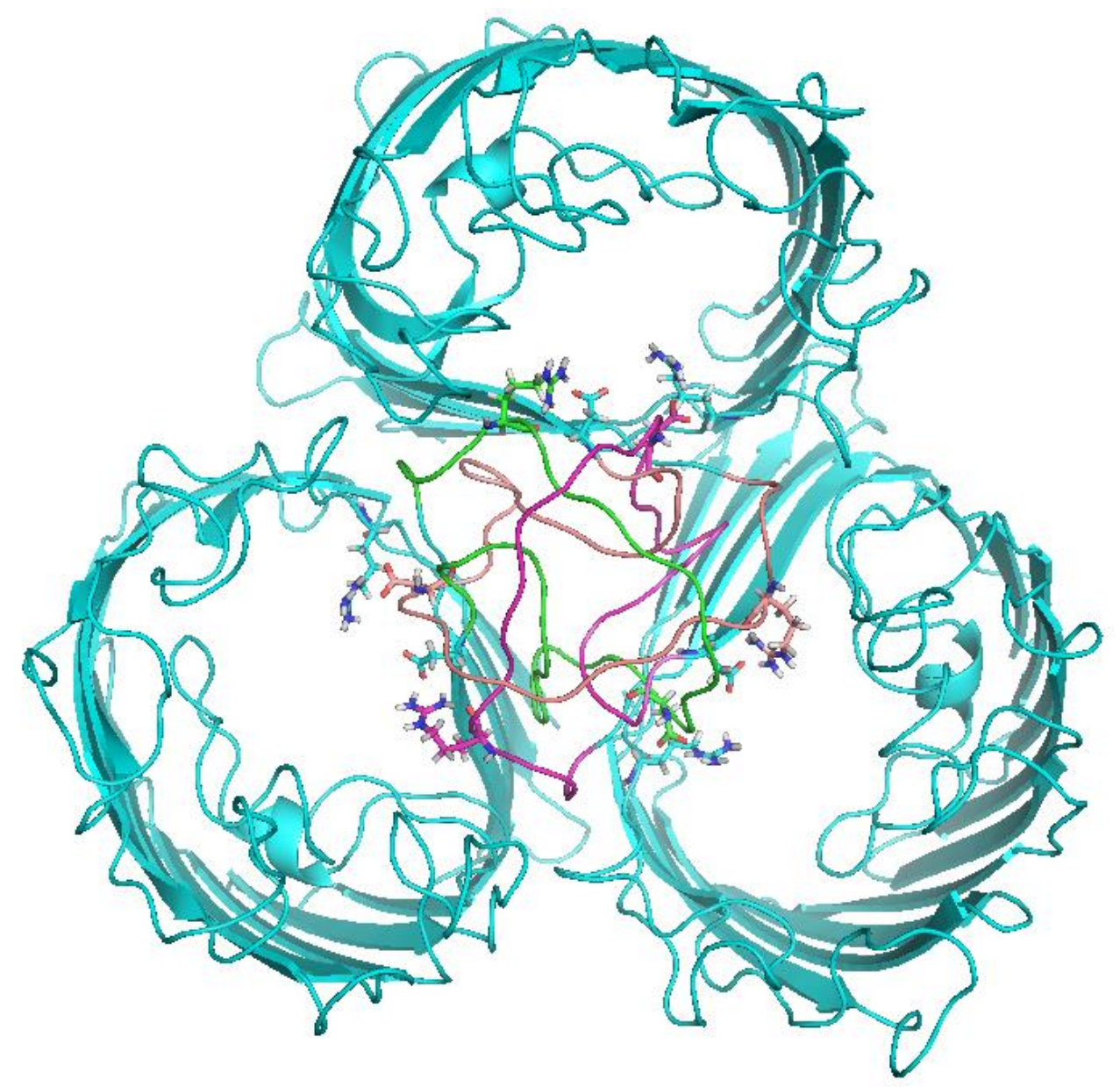

Figure 9: Omp2a trimer predicted by GalaxyGemini. The loop 2 of each monomer is pictured (green, magenta, rose) with the two stabilizing electrostatic interactions (R119...D143, D129...R87) at the interface monomer-monomer.
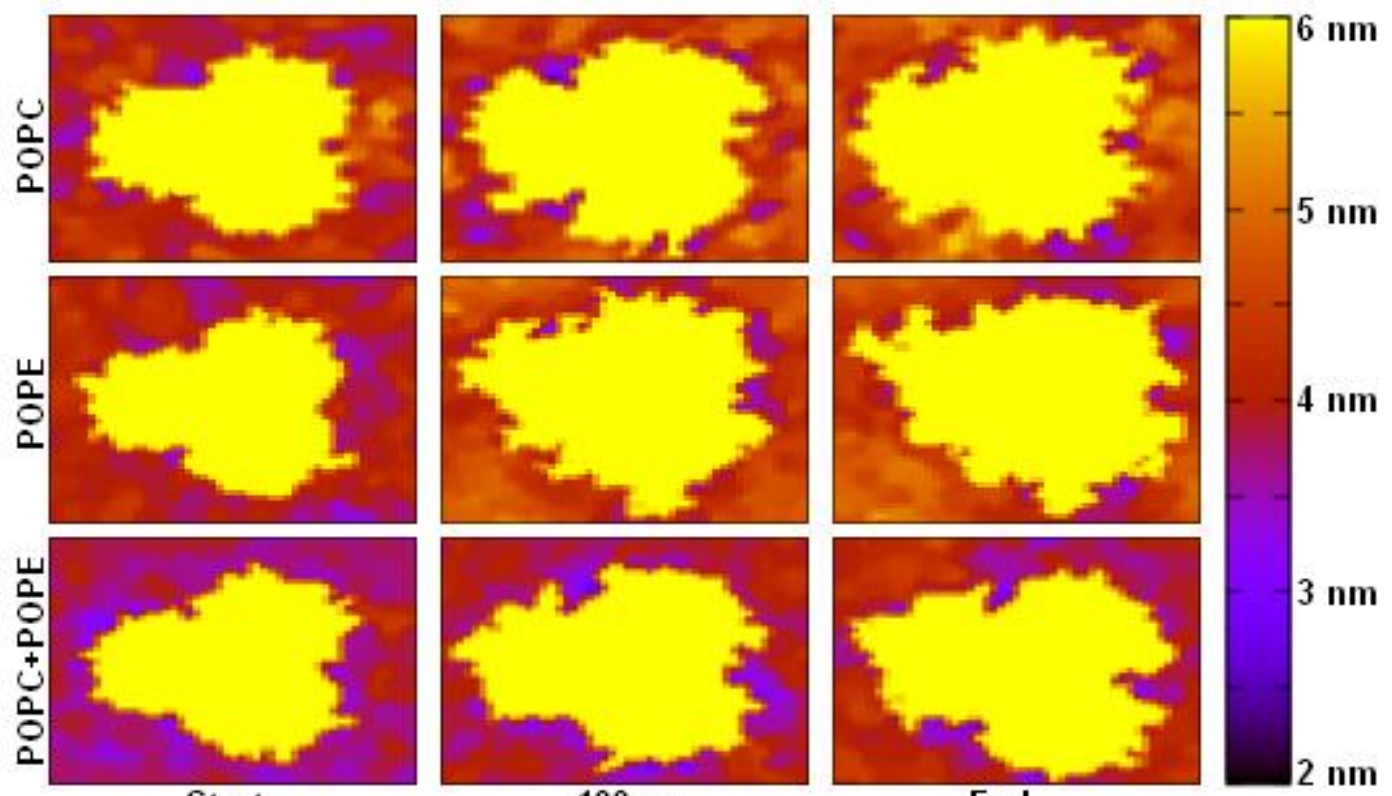

Start

$100 \mathrm{~ns}$

End

Figure 10: Top view of the trimers regarding the average membrane thickness. The thicknesses are calculated following the distance between phosphates on both sides of the membrane. (changer la partie "protéine") 


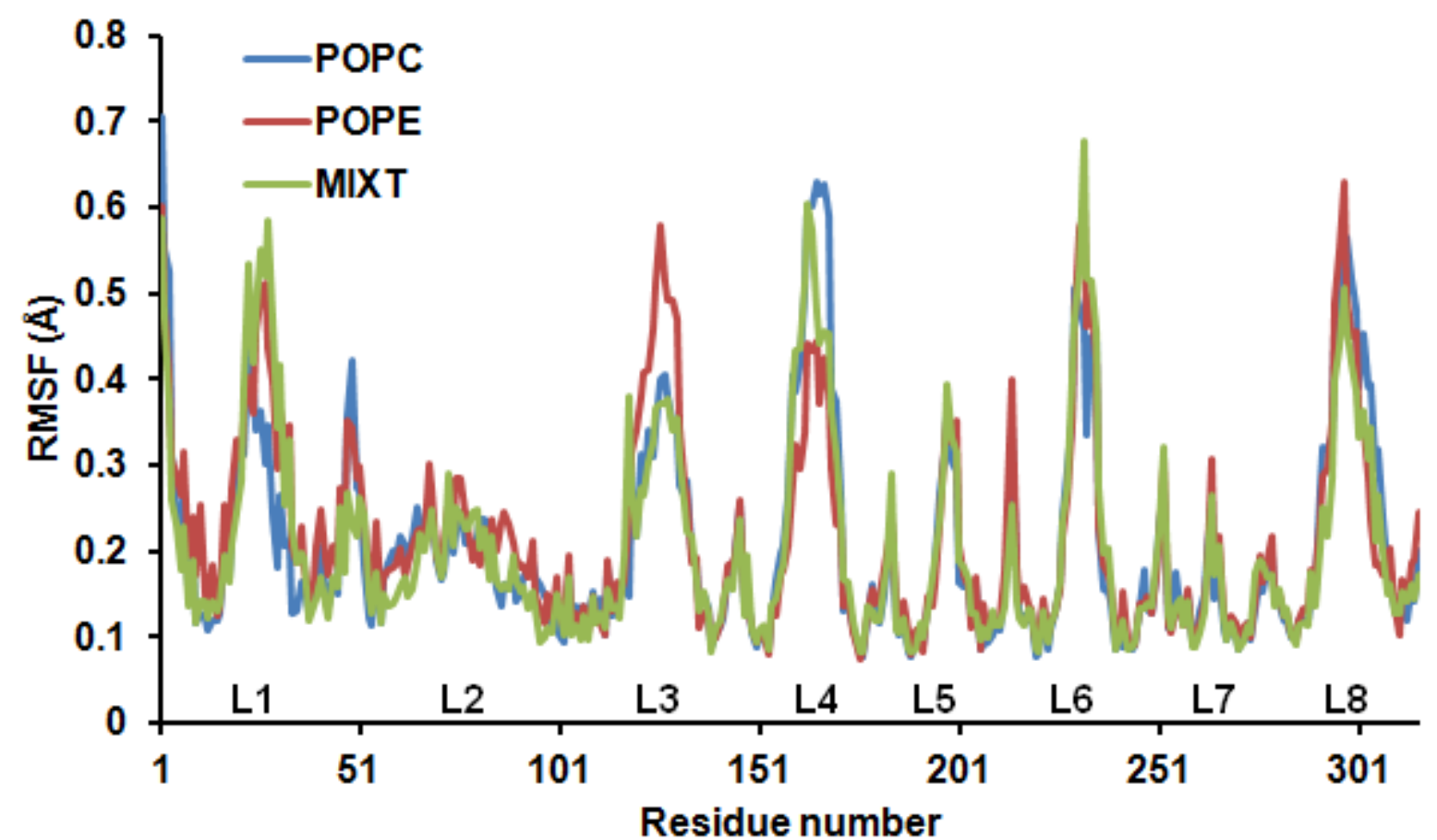

Figure 11: RMSF of Omp2a trimer in a POPC, POPE and POPC/E membrane. Values are averaged for the three monomers.

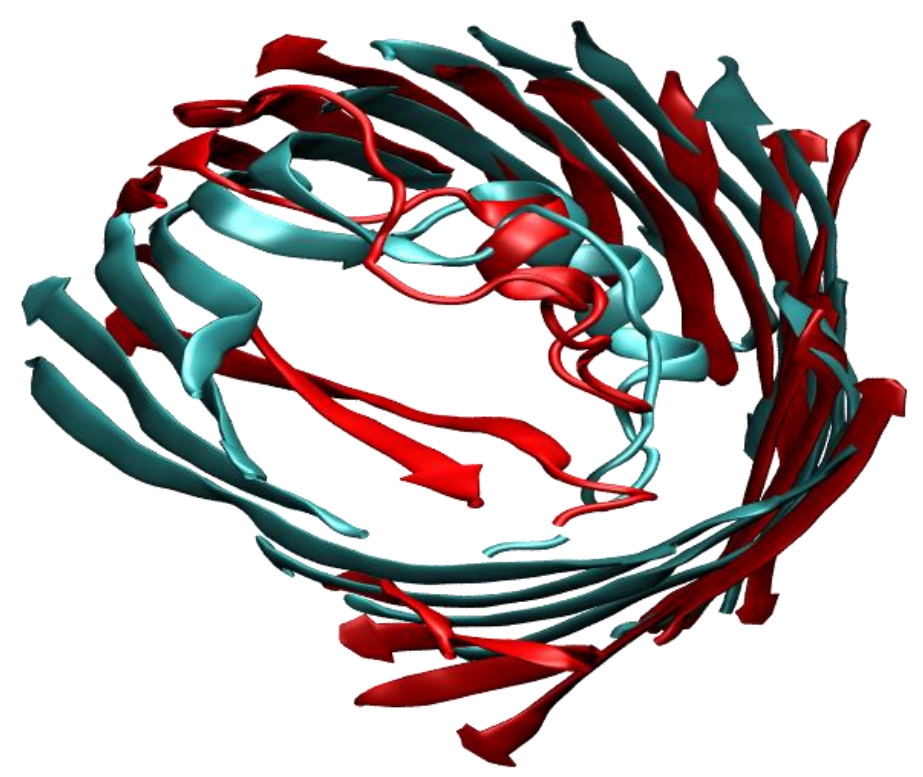

Figure 12: Superposition of the Omp2a model before (cyan) and after (red) simulation showing the shrinking of the constriction zone. (which membrane?) 
In the supplementary information?
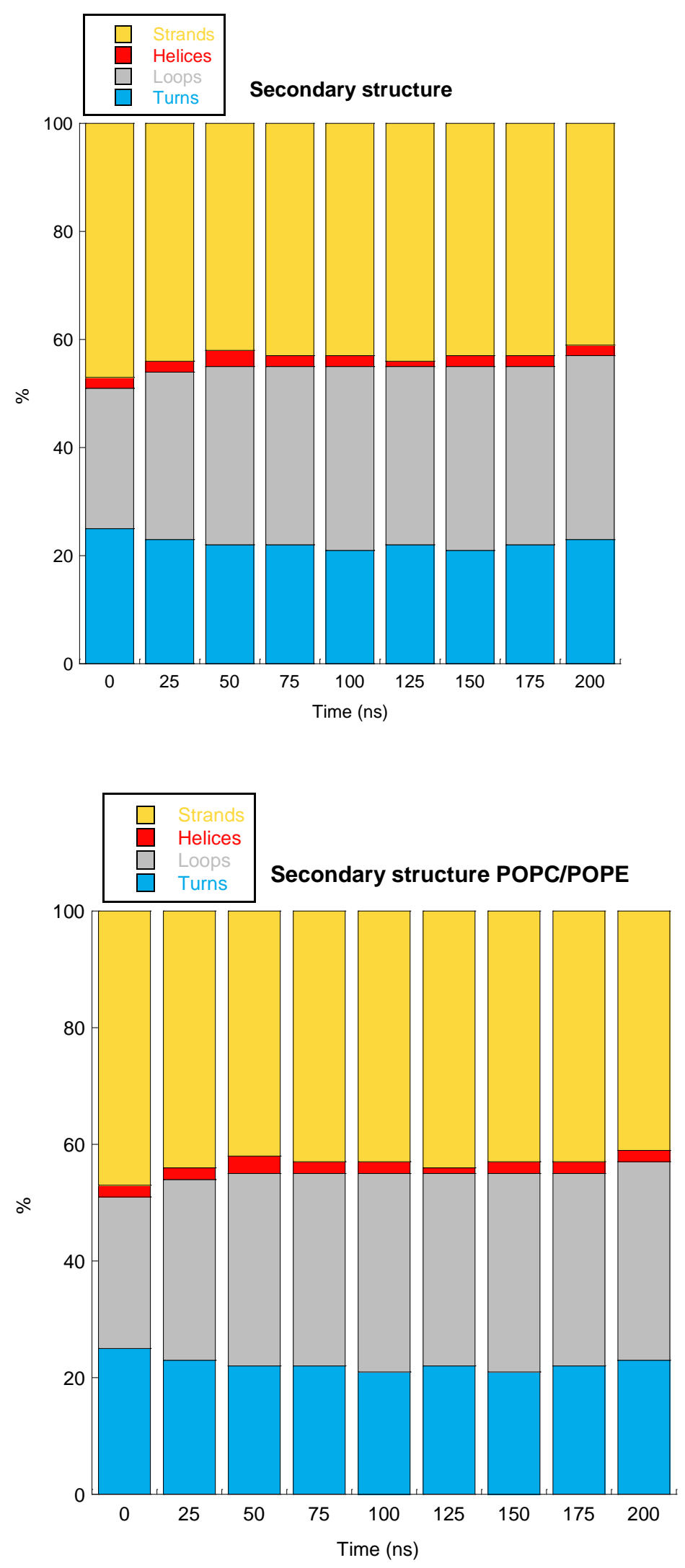

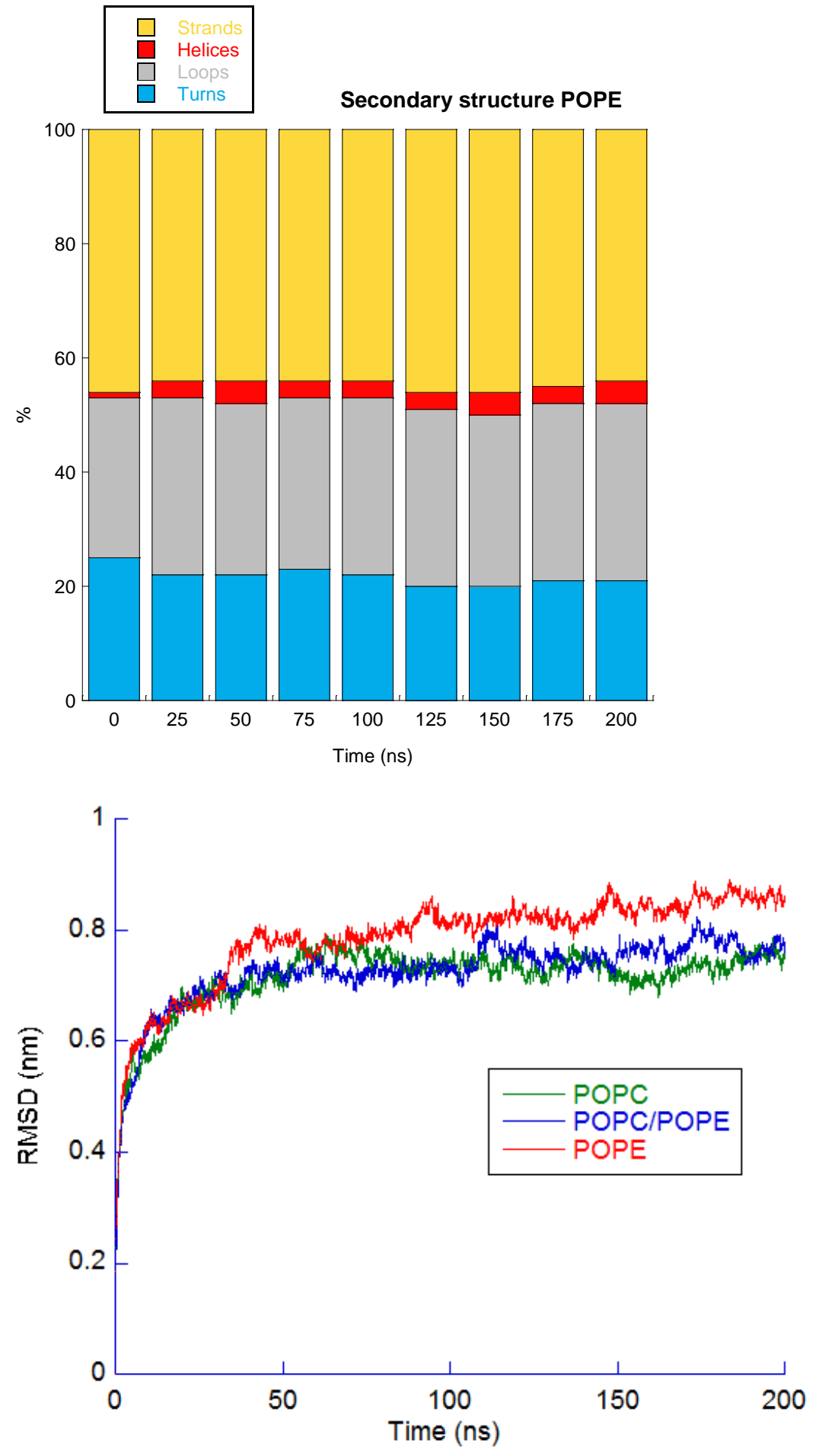
Bibliography

Abraham, M. J., Murtola, T., Schulz, R., Páll, S., Smith, J. C., Hess, B., \& Lindah, E. (2015). Gromacs: High performance molecular simulations through multi-level parallelism from $\begin{array}{llll}\text { laptops to supercomputers. } & \text { SoftwareX, } 19-25 .\end{array}$ http://doi.org/10.1016/j.softx.2015.06.001

Allen, W. J., Lemkul, J. A., \& Bevan, D. R. (2009). GridMAT-MD: A grid-based membrane analysis tool for use with molecular dynamics. Journal of Computational Chemistry, 30(12), 1952-1958. http://doi.org/10.1002/jcc.21172

Altschul, S. F., Gish, W., Miller, W., Myers, E. W., \& Lipman, D. J. (1990). Basic local alignment search tool. Journal of Molecular Biology, 215(3), 403-410. http://doi.org/10.1016/S0022-2836(05)80360-2

Balasubramaniam, D., Arockiasamy, A., Kumar, P. D., Sharma, A., \& Krishnaswamy, S. (2012). Asymmetric pore occupancy in crystal structure of OmpF porin from Salmonella typhi. $\begin{array}{llll}\text { Journal of } & \text { Structural }\end{array}$ http://doi.org/10.1016/j.jsb.2012.04.005

Berendsen, H. J. C., van der Spoel, D., \& van Drunen, R. (1995). GROMACS: A messagepassing parallel molecular dynamics implementation. Computer Physics Communications, 91(1-3), 43-56. http://doi.org/10.1016/0010-4655(95)00042-E

Bigelow, H. R., Petrey, D. S., Liu, J., Przybylski, D., \& Rost, B. (2004). Predicting transmembrane beta-barrels in proteomes. Nucleic Acids Research, 32(8), 2566-2577. http://doi.org/10.1093/nar/gkh580

Cowan, S. W., Schirmer, T., Rummel, G., Steiert, M., Ghosh, R., Pauptit, R. A., ... Rosenbusch, J. P. (1992). Crystal structures explain functional properties of two E. coli porins. Nature, 358(6389), 727-733. http://doi.org/10.1038/358727a0

De Figueiredo, P., Ficht, T. A., Rice-Ficht, A., Rossetti, C. A., \& Adams, L. G. (2015). Pathogenesis and immunobiology of brucellosis: Review of Brucella-host interactions. $\begin{array}{llll}\text { American Journal of 1505-1517. } & \text { 185(6), }\end{array}$ http://doi.org/10.1016/j.ajpath.2015.03.003

DelVecchio, V. G., Kapatral, V., Redkar, R. J., Patra, G., Mujer, C., Los, T., ... Overbeek, R. (2002). The genome sequence of the facultative intracellular pathogen Brucella melitensis. Proceedings of the National Academy of Sciences of the United States of America, 99(1), 443-448. http://doi.org/10.1073/pnas.221575398 
Dhakshnamoorthy, B., Raychaudhury, S., Blachowicz, L., \& Roux, B. (2010). Cation selective pathway of OmpF porin revealed by anomalous X-ray diffraction. Journal of Molecular Biology, 396(2)(October 2009), 293-300. http://doi.org/10.1007/s11103-011-9767z.Plastid

Essmann, U., Perera, L., Berkowitz, M. L., Darden, T., Lee, H., \& Pedersen, L. G. (1995). A smooth particle mesh Ewald method. The Journal of Chemical Physics, 103(19), 85778593. http://doi.org/10.1063/1.470117

Feher, V. a, Randall, A., Baldi, P., Bush, R. M., de la Maza, L. M., \& Amaro, R. E. (2013). A 3dimensional trimeric $\beta$-barrel model for Chlamydia MOMP contains conserved and novel elements of Gram-negative bacterial porins. PloS One, 8(7), e68934. http://doi.org/10.1371/journal.pone.0068934

Galdiero, S., Falanga, A., Cantisani, M., Tarallo, R., Elena Della Pepa, M., D’Oriano, V., \& Galdiero, M. (2012). Microbe-Host Interactions: Structure and Role of Gram-Negative Bacterial Porins. Current Protein and Peptide Science, 13(8), 843-854. http://doi.org/10.2174/138920312804871120

Hess, B., Bekker, H., Berendsen, H. J. C., \& Fraaije, J. G. E. M. (1997). LINCS: A linear constraint solver for molecular simulations. Journal of Computational Chemistry, 18(12), 1463-1472. http://doi.org/10.1002/(SICI)1096-987X(199709)18:12<1463::AID$\mathrm{JCC} 4>3.0 . \mathrm{CO} ; 2-\mathrm{H}$

Huang, J., \& Mackerell Jr, A. D. (2013). CHARMM36 all-atom additive protein force field: Validation based on comparison to NMR data Jing. Journal of Computational Chemistry, 34(25), 2135-2145. http://doi.org/10.1007/s11103-011-9767-z.Plastid

Humphrey, W., Dalke, A., \& Schulten, K. (1996). VMD: Visual molecular dynamics. Journal of Molecular Graphics, 14(1), 33-38. http://doi.org/10.1016/0263-7855(96)00018-5

Im, W., \& Roux, B. (2002a). Ion permeation and selectivity of OmpF porin: A theoretical study based on molecular dynamics, Brownian dynamics, and continuum electrodiffusion theory. Journal of Molecular Biology, 322(4), 851-869. http://doi.org/10.1016/S0022-2836(02)00778-7

Im, W., \& Roux, B. (2002b). Ions and counterions in a biological channel: A molecular dynamics simulation of ompf porin from Escherichia coli in an explicit membrane with 1 $\mathrm{M} \mathrm{KCl}$ aqueous salt solution. Journal of Molecular Biology, 319(5), 1177-1197. http://doi.org/10.1016/S0022-2836(02)00380-7 
Jackups, R., \& Liang, J. (2005). Interstrand pairing patterns in $\beta$-barrel membrane proteins: The positive-outside rule, aromatic rescue, and strand registration prediction. Journal of Molecular Biology, 354(4), 979-993. http://doi.org/10.1016/j.jmb.2005.09.094

Jeanteur, D., Lakey, J. H., \& Pattus, F. (1991). The bacterial porin superfamily: sequence alignment and structure prediction. Molecular Microbiology, 5(9), 2153-2164. http://doi.org/10.1111/j.1365-2958.1991.tb02145.x

Jo, S., Kim, T., \& Im, W. (2007). Automated Builder and Database of Protein/Membrane Complexes for Molecular Dynamics Simulations. PLoS ONE, 2(9), e880. http://doi.org/10.1371/journal.pone.0000880

G. Jones, P. Willett, R. C. Glen, A. R. Leach and R. Taylor, J. Mol. Biol., 267, 727-748, 1997 Development and Validation of a Genetic Algorithm for Flexible Docking

Källberg, M., Wang, H., Wang, S., Peng, J., Wang, Z., Lu, H., \& Xu, J. (2012). Template-based protein structure modeling using the RaptorX web server. Nature Protocols, 7(8), 151122. http://doi.org/10.1038/nprot.2012.085

Koebnik, R., Locher, K. P., \& Van Gelder, P. (2000). Structure and function of bacterial outer membrane proteins: barrels in a nutshell. Molecular Microbiology, 37(2), 239-253. http://doi.org/10.1046/j.1365-2958.2000.01983.x

Korkmaz, F., Köster, S., Yildiz, Ö.", \& Mäntele, W. (2008). The role of lipids for the functional integrity of porin: An FTIR study using lipid and protein reporter groups. Biochemistry, 47(46), 12126-12134. http://doi.org/10.1021/bi801224y

Lee, H., Park, H., Ko, J., \& Seok, C. (2013). GalaxyGemini: A web server for protein homooligomer structure prediction based on similarity. Bioinformatics, 29(8), 1078-1080. http://doi.org/10.1093/bioinformatics/btt079

Leekumjorn, S., \& Sum, A. K. (2007). Molecular characterization of gel and liquid-crystalline structures of fully hydrated POPC and POPE bilayers. Journal of Physical Chemistry B, 111(21), 6026-6033. http://doi.org/10.1021/jp0686339

Lopes-Rodrigues, M., Triguero, J., Torras, J., Perpète, E. A., Michaux, C., Zanuy, D., \& Alemán, 
C. (2018). Influence of the surrounding environment in re-naturalized $\beta$-barrel membrane proteins. Biophysical Chemistry, 234(January), 6-15. http://doi.org/10.1016/j.bpc.2017.12.003

Lovell, S. C., Davis, I. W., Adrendall, W. B., de Bakker, P. I. W., Word, J. M., Prisant, M. G., ... Richardson, D. C. (2003). Structure validation by C alpha geometry: phi,psi and C beta deviation. Proteins-Structure Function and Genetics, 50(August 2002), 437-450. http://doi.org/10.1002/prot.10286

Ma, J., Wang, S., Zhao, F., \& Xu, J. (2013). Protein threading using context-specific alignment potential. Bioinformatics, 29(13). http://doi.org/10.1093/bioinformatics/btt210

Marquis, H., \& Ficht, T. A. (1993). The omp2 gene locus of Brucella abortus encodes two homologous outer membrane proteins with properties characteristic of bacterial porins. Infection and Immunity, 61(9), 3785-3790.

Mobasheri, H., Ficht, T. a., Marquis, H., Lea, E. J. a, \& Lakey, J. H. (1997). Brucella Omp2a and Omp2b porins: Single channel measurements and topology prediction. FEMS Microbiology Letters, 155, 23-30. http://doi.org/10.1016/S0378-1097(97)00341-8

Moraes, I., Evans, G., Sanchez-weatherby, J., Newstead, S., \& Shaw, P. D. (2014). Membrane protein structure determination - The next generation. BBA - Biomembranes, 1838(1), 78-87. http://doi.org/10.1016/j.bbamem.2013.07.010

Moriyón, I., \& López-Goñi, I. (1998). Structure and properties of the outer membranes of Brucella abortus and Brucella melitensis. International Microbiology, 1(1), 19-26.

Niramitranon, J., Sansom, M. S., \& Pongprayoon, P. (2016). Why do the outer membrane proteins OmpF from E. coli and OprP from P. aeruginosa prefer trimer? Simulation studies. Journal of Molecular Graphics and Modelling, 65, 1-7. http://doi.org/10.1016/j.jmgm.2016.02.002

Pagès, J.-M., James, C. E., \& Winterhalter, M. (2008). The porin and the permeating antibiotic: a selective diffusion barrier in Gram-negative bacteria. Nature Reviews. Microbiology, 6(12), 893-903. http://doi.org/10.1038/nrmicro1994

Pappas, G., Papadimitriou, P., Akritidis, N., Christou, L., \& Tsianos, E. V. (2006). The new global map of human brucellosis, 6(February), 91-99.

Paquet, J. Y., Vinals, C., Wouters, J., Letesson, J. J., \& Depiereux, E. (2000a). Topology prediction of Brucella abortus Omp2b and Omp2a porins after critical assessment of transmembrane beta strands prediction by several secondary structure prediction 
methods. Journal of Biomolecular Structure \& Dynamics, 17(October 2014), 747-757. http://doi.org/10.1080/07391102.2000.10506564

Paquet, J. Y., Vinals, C., Wouters, J., Letesson, J. J., \& Depiereux, E. (2000b). Topology prediction of Brucella abortus Omp2b and Omp2a porins after critical assessment of transmembrane beta strands prediction by several secondary structure prediction methods. Journal of Biomolecular Structure \& Dynamics, 17, 747-757. http://doi.org/10.1080/07391102.2000.10506564

Pathak P, Kumar A, Thavaselvam D. BMC Infect Dis. 2017 Jul 11;17(1):485. Evaluation of recombinant porin (rOmp2a) protein as a potential antigen candidate for serodiagnosis of Human Brucellosis.

Pérez-Madrigal, M. M., del Valle, L. J., Armelin, E., Michaux, C., Roussel, G., Perpète, E. a., \& Alemán, C. (2015). Polypyrrole-Supported Membrane Proteins for Bio-Inspired Ion Channels. ACS Applied Materials \& Interfaces, 7, 1632-1643. http://doi.org/10.1021/am507142f

Phale PS, Philippsen A, Kiefhaber T, Koebnik R, Phale VP, Schirmer T, Rosenbusch JP.

Biochemistry. 1998 Nov 10;37(45):15663-70. Stability of trimeric OmpF porin: the contributions of the latching loop L2

Phale, P. S., Philippsen, A., Widmer, C., Phale, V. P., Rosenbusch, J. P., \& Schirmer, T. (2001). Role of charged residues at the OmpF porin channel constriction probed by mutagenesis and simulation. Biochemistry, 40(21), 6319-6325. http://doi.org/10.1021/bi010046k

Puiggalí-jou, A., Pérez-madrigal, M. M., Valle, L. J., Armelin, E., Casas, M. T., Michaux, C., ... Alemán, C. (2016). Confinement of a $\beta$-barrel protein in nanoperforated free-standing nanomembranes for ion transport. Nanoscale, 8, 16922-16935. http://doi.org/10.1039/c6nr04948f.Please

Roussel, G., Matagne, A., De Bolle, X., Perpète, E. a., \& Michaux, C. (2012a). Purification, refolding and characterization of the trimeric Omp2a outer membrane porin from 
Brucella melitensis. Protein Expression and Purification, 83(2), 198-204. http://doi.org/10.1016/j.pep.2012.04.003

Roussel, G., Matagne, A., De Bolle, X., Perpète, E. A., \& Michaux, C. (2012b). Purification, refolding and characterization of the trimeric Omp2a outer membrane porin from Brucella melitensis. Protein Expression and Purification, 83(2), 198-204. http://doi.org/10.1016/j.pep.2012.04.003

Roussel, G., Perpète, E. A., Matagne, A., Tinti, E., \& Michaux, C. (2013). Towards a universal method for protein refolding: The trimeric beta barrel membrane Omp2a as a test case. Biotechnology and Bioengineering, 110(2), 417-423. http://doi.org/10.1002/bit.24722

Schulz, G. E. (2000). beta-Barrel membrane proteins. Current Opinion in Structural Biology, 10(4), 443-447. http://doi.org/DOI: 10.1016/S0959-440X(00)00120-2

Shin, W.-H., Lee, G. R., Heo, L., Lee, H., \& Seok, C. (2014). Prediction of Protein Structure and Interaction by GALAXY Protein Modeling Programs. Bio Design, 2, 01-11. Retrieved from http://www.bdjn.org/Journal_File_Dir/Sub/j_sub_pdf_file_f69ad773_.pdf

Smart, O. S., Neduvelil, J. G., Wang, X., Wallace, B. A., \& Sansom, M. S. P. (1996). HOLE: A program for the analysis of the pore dimensions of ion channel structural models. Journal of Molecular Graphics, 14(6), 354-360. http://doi.org/10.1016/S02637855(97)00009-X

Tamm, L. K., Hong, H., \& Liang, B. (2004). Folding and assembly of beta-barrel membrane proteins. Biochimica et Biophysica Acta - Biomembranes, 1666(1), 250-263. http://doi.org/10.1016/j.bbamem.2004.06.011

Tien, H. T., \& Ottova-Leitmannova, A. (2003). Planar lipid bilayers (BLMs) and their applications. Elsevier.

Touw, W. G., Baakman, C., Black, J., Te Beek, T. A. H., Krieger, E., Joosten, R. P., \& Vriend, G. (2015). A series of PDB-related databanks for everyday needs. Nucleic Acids Research, 43(D1), D364-D368. http://doi.org/10.1093/nar/gku1028

Varma, S., Chiu, S.-W., \& Jakobsson, E. (2006). The Influence of Amino Acid Protonation States on Molecular Dynamics Simulations of the Bacterial Porin OmpF. Biophysical Journal, 90(1), 112-123. http://doi.org/10.1529/biophysj.105.059329

Vollan, H. S., Tannæs, T., Vriend, G., \& Bukholm, G. (2016). In silico structure and sequence analysis of bacterial porins and specific diffusion channels for hydrophilic molecules: 
Conservation, multimericity and multifunctionality. International Journal of Molecular Sciences, 17(4). http://doi.org/10.3390/ijms17040599

Zeth, K., \& Thein, M. (2010). Porins in Prokaryotes and Eukaryotes: Common Themes and Variations. The Biochemical Journal, 431(1), 13-22. http://doi.org/10.1042/BJ20100371 